\title{
La servidumbre por deuda en el ámbito rural del sur de la India
}

\author{
David Picherit
}

Se explora cómo los trabajadores rurales migrantes en el sur de la India negocian y conciben el endeudamiento en un contexto de relaciones de empleo y de poder cambiantes. El rechazo a ataduras, su búsqueda de dignidad y la transformación de la migración laboral se combinan con las relaciones renovadas de patronazgo en el contexto de pobreza estructural y precariedad. Esto los conduce a formas diversas de empleo, crédito y protección. A través de un estudio de caso etnográfico de trabajadores migrantes se muestra cómo las reformulaciones de la protección a los trabajadores y las relaciones de poder que implican son cruciales para comprender los límites entre endeudamiento y sobreendeudamiento. Se argumenta que el sobreendeudamiento aparece cuando la obligación moral de pagar se combina con la ausencia de protección estable y un quebranto eventual del estatus.

PALABRAS CLAVE: servidumbre por deuda, trabajo, migraciones laborales, India, programas de desarrollo

\section{Debt-bondage in Rural South India}

The article explores how migrant rural workers in South India negotiate and conceive indebtedness in the context of changing labor and power relations. Laborers' rejection of personalized attachment, their quest for dignity and the transformation of labor migration, combined with renovated patronage relationships in the context of structural poverty and precariousness lead to a constant search for multiple and temporary protection, work and credit. An ethnographical case study conducted among migrant laborers shows how the reformulations of protection forms for laborers and thus of power relations are crucial to understand the limits between indebtedness and overindebtedness. We argue that overindebtedness appears when the moral and physical obligation to reimburse a debt is combined with the absence of dependable protection and an eventual decline of status.

KEYWORDS: debt-bondage, labour, labour migration, India, development programs

David Picherit: École des Hautes Études en Sciences Sociales, Centre d’Études de l'Inde et de l'Asie du Sud, París, Francia picheritdavid@gmail.com

Traducción: Pastora Rodríguez Aviñoá

Desacatos, núm. 44, enero-abril 2014, pp. 83-102

Recepción: 23 de abril de 2012 / Aceptación: 30 de septiembre de 2013 


\section{INTRODUCCIÓN}

$\mathrm{E}$ 1 proceso de liberalización iniciado en la India a finales de la década de 1980 y el dinamismo de su economía han sido mucho más ponderados que otras transformaciones contemporáneas en ese país, como la informalización del trabajo, la creciente migración interna y el desarrollo de nuevas formas de servidumbre por deuda en sectores capitalistas de la economía (Breman, 1996; Harriss-White, 2003; Breman, Guérin y Prakash, 2009). En este caso se encuentra Andhra Pradesh, un estado en la India meridional que se ha colocado a la vanguardia de las políticas neoliberales desde 1994. Descrito por los organismos internacionales y el gobierno como un estado ineficiente, burocrático y corrupto, hubo de transformarse en un "facilitador" para atraer a compañías multinacionales, sobre todo industrias de alta tecnología y agencias de desarrollo. Para ello echó a andar un alud de programas de combate a la pobreza y de planes de desarrollo a fin de mitigar los efectos adversos de las políticas neoliberales sobre la población de bajos recursos. El microcrédito se volvió la palabra clave de las políticas de desarrollo con su ideología de "autoayuda": los pobres, que asumían su responsabilidad en su situación, eran animados a cambiar sus manejos financieros para salir de la pobreza (Elyachar, 2002). Después de 15 años, el éxito y la caída del microcrédito ${ }^{1}$ tuvieron un impacto profundo en la manera en que las empresas perciben en la actualidad a los pobres: si logran ahorrar, pueden adquirir productos. A menudo vista como la encarnación del atraso, la India rural es hoy en día centro de atención de actores económicos, que la consideran un mercado habitado por empresarios y consumidores. Las compañías multinacionales, como Godrej, Danone o el American International Group, diseñan productos tecnológicos específicos para la población rural pobre - vendidos por

\footnotetext{
${ }^{1}$ Andhra Pradesh fue el primer estado en términos de número de
} grupos de autoayuda. medio de estrategias innovadoras y sociedades con bancos, organizaciones no gubernamentales (ONG), organismos estatales e internacionales-, productos de salud y seguros de vida. Estas alianzas en el sector de protección de los pobres emergen con otros programas que garantizan 100 días de trabajo al año para la población rural pobre. De cualquier modo, no ha cambiado un ápice el hecho de que menos de 6\% de esos trabajadores gozan de acceso a protección general, ya sea por el sindicalismo, el seguro, los planes de jubilación ofrecidos por el Estado, las ONG o las compañías privadas. El acceso a la tarjeta de ayuda alimenticia, a los programas sociales de salud o de trabajo depende en gran medida de las formas locales de clientelismo político.

El panorama de la protección de los trabajadores se ha transformado en los últimos 20 años. Los asuntos de protección atraviesan dicotomías entre seguridad social estatal, programas de oNG y clientelismo, y se articulan con relaciones laborales y sociales cambiantes. Las fronteras borrosas entre la protección que ofrece el Estado, el mercado, las políticas públicas y las ong y la que los trabajadores buscan no significa que éstas sean equivalentes. En cualquier caso, me interesa examinar cómo los trabajadores tratan de asegurar sus modos de vida futuros al movilizar y alternar diferentes tipos de capital —social, político, religioso y económico-, como el Estado, la casta, la familia, las oNG, los prestamistas, los terratenientes y los partidos políticos. Todas esas protecciones implican diferentes grados de dominación, jerarquías, valores y dependencias para trabajadores comprometidos por servidumbres de deuda, que a menudo entrañan una actitud de deferencia y servicio, así como humillaciones y violencia simbólica. La reestructuración de la mano de obra, el desarrollo y el consumo por parte del capitalismo en la India ejerce mucha presión en las finanzas de la población rural pobre y el sobreendeudamiento aparece como uno de los asuntos críticos en los años venideros.

Este vínculo entre deuda y formas de protección en los mundos laborales es una relación social de 
poder con temporalidades, grados de coerción y acción y modos de manipulación de distinta índole. Como parte de modalidades de transacción más amplias, tanto monetarias como no monetarias, las deudas están ligadas a la casta, a las posiciones de clase y de género, a las obligaciones y las controversias. Eso da a la deuda una multiplicidad de valores, significados y prácticas, articuladas a la sociedad y la economía (Zelizer, 1994; Bloch y Parry, 1989; Bourdieu, 1976). A través de una etnografía de los trabajadores atados por deudas que migran temporalmente a trabajar en el sector de la construcción, que vive un repentino auge en las áreas rurales y urbanas, en este ensayo se exploran los significados y las acciones en torno a la deuda a partir de las relaciones dinámicas entre formas de trabajo y modos de protección de los jornaleros temporales migrantes. Se analiza el impacto de la reconfiguración de las relaciones de trabajo y de protección en la manera en que las relaciones sociales de deuda se manipulan, se negocian y se viven por parte de los empleadores y de los trabajadores atados por deudas en circunstancias de explotación extrema y las formas extraeconómicas de coerción.

Este artículo se basa en 24 meses de trabajo de campo etnográfico llevado a cabo en un pueblo del distrito de Mahabubnagar, Andhra Pradesh. Durante ese periodo, seguí a diferentes grupos de jornaleros migrantes - atados por deudas, eventuales o pagados a destajo - que trabajaban en la industria de la construcción rural y urbana, y compartí sus vidas cotidianas en los lugares de migración y de trabajo. Fui y vine con ellos a sus pueblos. ${ }^{2}$ Peddapur es una localidad de 2500 habitantes ubicada a 150 kilómetros de Hyderabad y a 20 kilómetros de la ciudad más cercana: de 60 a $80 \%$ de la población en edad de trabajar - de 15 a 45 años, hombres y mujeres-, la mayoría de las castas inferiores - Madigas, exintocables, y Gollas, castas atrasadasmigran estacionalmente con diferentes arreglos

${ }^{2}$ La observación cotidiana, las discusiones informales y formales fueron las principales herramientas utilizadas en este estudio. laborales. ${ }^{3}$ El grueso de la economía del pueblo y de las relaciones sociales depende de la migración laboral. En este distrito, uno de los más pobres y susceptibles a las sequías de la India, ${ }^{4}$ la organización de la migración laboral en la industria de la construcción por parte de los terratenientes - casta Reddy - dista de ser un negocio nuevo. De la década de 1930 en adelante desarrollaron un sistema de servidumbre por deudas llamado palamur para poner a trabajar a Madigas y Gollas en los principales canales de riego y presas de la India. Esta práctica, común en la era colonial (Behal y van der Linden, 2007), cambió en los noventa del siglo xx gracias a la reconfiguración del capitalismo en la India. Las perspectivas de beneficios elevados en el sector de la construcción llevaron a los Reddys a ajustar sus inversiones de capital a los nuevos requerimientos de la industria de la construcción, así como a adaptar sus modos de dominación a las cambiantes relaciones de casta y de clase.

La implementación del capitalismo en la India ha adquirido diversas formas y los líderes locales han desempeñado un papel estratégico al imprimirle características específicas en lugares particulares y combinar diferentes modos de dominación. El sistema de servidumbre por deudas, actualmente menos personalizado, con bases monetarias más fuertes debido al desvanecimiento de las relaciones de patronazgo, se ha articulado a la creciente circulación de trabajadores eventuales en la industria de la construcción urbana. Este proceso dual de mano de obra libre y formas peculiares de adhesión, segmentado de conformidad con categorías de casta y de clase, se encuentra integrado en un continuo

\footnotetext{
${ }^{3}$ Castas inventariadas - como Madigas-, clases atrasadas - como Gollas - o clases progresistas - como Reddy - son categorías administrativas. Dalits, "oprimidos", es un término político sobre todo en los campos del desarrollo y la política, rara vez usado por la gente misma para referirse a su casta.

${ }^{4}$ Palamur, el antiguo nombre del distrito de Mahabubnagar (1929), solía aludir al sistema de servidumbre por deuda y ha sido apropiado por todos los trabajadores manuales provenientes de ahí.
} 
escalonado según grados de dependencia múltiples y temporales (Lerche, 2010).

El desvanecimiento del patronazgo afectó profundamente las relaciones laborales. Si bien es común que los trabajadores alternen entre los sistemas de mano de obra temporal y de servidumbre por deudas, todos los trabajadores de Peddapur sufren la misma falta de protección y la carencia de movimientos sociales, sindicales o movimientos Dalits. Los empleadores han reducido los costos de protección y ésta en general se ha reconfigurado mediante planes de lucha contra la pobreza - microcrédito, préstamos hipotecarios, tarjetas de ayuda alimenticia, etc.-. En circunstancias en las que los trabajadores migrantes, ya sea temporales o subyugados por deudas, se ausentan nueve meses al año, el grueso de los programas de ayuda es acaparado y redistribuido por empleadores-terratenientes-políticos de acuerdo con el clientelismo político y con cálculos de casta, género y clase. Mientras que los trabajadores migrantes están involucrados con formas de trabajo y dependencia cortoplacistas, irregulares e inseguras, esos programas se han convertido en una herramienta para controlar la mano de obra.

Dichas estrategias emergentes de protección han reestructurado los significados, los espacios sociales y las lógicas de la deuda, para convertirla en un elemento clave de las relaciones cotidianas entre castas y clases. Al comparar las diversas modalidades de manipulación de la deuda con las formas laborales, sostengo que la monetización de las relaciones laborales, aunada a la falta de protección, fomenta múltiples deudas, pequeñas y de corto plazo, como parte de modos articulados de dependencia y dominio. La limitada capacidad de negociación de los trabajadores y la obligación moral, violenta y material de resarcir una deuda transforman cualquier deuda particular en endeudamiento prolongado tan pronto como los trabajadores carentes de seguridad social enfrentan gastos inesperados o un accidente grave.

La primera parte de este artículo explora la relación entre monetización de la relación y protección de la mano de obra libre y de la no emancipada. La segunda investiga los modos cambiantes de dominación por parte de terratenientes-maistris-políticos en circunstancias en que privan formas emergentes de circulación de la mano de obra. Las partes tercera y cuarta detallan la diferenciación entre trabajadores subyugados por deuda y cómo se manipula ésta. En la quinta discuto el surgimiento y la caída de una familia, la servidumbre por deudas hasta la agricultura y retorno a la servidumbre, su tránsito de la deuda al sobreendeudamiento. La última parte describe el proceso mediante el cual los trabajadores intentan acceder a los programas gubernamentales en el pueblo.

\section{MONETIZACIÓN DE LAS RELACIONES Y PROTECCIÓN}

En la literatura, la servidumbre por deuda, como categoría, se atribuye a menudo a un grupo homogéneo de trabajadores que comparten más o menos las mismas condiciones. Esta homogeneidad ha sido profundamente cuestionada por las dificultades explícitas de definir la servidumbre por deuda y la escala de la servidumbre en la India, que oscila entre 12 y 50 millones de personas (Lerche, 2007). La duración y la entrada y/o salida del sistema de servidumbre son algunos de los criterios que diferencian la definición de la Organización Mundial del Trabajo (OIT), según economistas y antropólogos, lo que destaca de manera indirecta la multitud de posiciones sociales dentro de la categoría, así como el ajuste constante de la servidumbre por deuda a las transformaciones de la economía.

El debate acerca de la mano de obra libre y la no emancipada ha recibido en años recientes una renovada atención en la India. Mientras que los economistas clásicos niegan la compatibilidad de la mano de obra no emancipada con el capitalismo, los marxistas la consideran parte de las formas precapitalistas de producción (Lerche, 2007). Otros académicos 
han mostrado con detalle que la servidumbre por deudas no sólo es una parte integral del sistema capitalista (Kapadia, 1995), sino que argumentan que el capitalismo "en ciertas situaciones de hecho prefiere ésta a una fuerza de trabajo libre" (Brass, 1994: 225). Según Brass, "la comoditización - mercantilización- de la mano de obra se ve cercenada mediante formas de adhesión y no libertad del trabajador" (Brass, 1990: 37), lo que denomina un proceso de desproletarización. Breman describe más bien la desaparición de formas no emancipadas en la agricultura y su reintroducción en varios sectores capitalistas (Breman, 1996; 2007). Esas nuevas modalidades de servidumbre son "menos personalizadas, más contractuales y monetizadas" y han disminuido la protección por medio del patronazgo (Breman, 1996: 169).

Esta neoservidumbre, sobre todo la monetización de las relaciones sociales y las negociaciones entre trabajadores y empleadores a propósito de adelantos de efectivo, ha recibido una gran atención (Breman, Guérin y Prakash, 2009). Mientras que Breman señala que "la deuda es manipulada como un instrumento de coerción” (Breman, 1996: 169), De Neve (1999) y Carswell y De Neve (2013) destacan convincentemente el hecho de que los trabajadores también pueden, en las pujantes industrias textiles de pequeña escala, manipular e incluso aprovechar los adelantos de efectivo. Guérin muestra que las crecientes negociaciones de deuda se relacionan en diferente grado con la no emancipación en las unidades de cultivo de caña, ladrilleras y secadoras manuales de arroz (Guérin, Morvant-Roux y Villarreal, 2013). Describe cómo los trabajadores escamotean e incurren en deudas, utilizan su capacidad de poner en entredicho, a veces sólo tangencialmente, las relaciones de poder $y$ afirman su dignidad en circunstancias de mercados crediticios fragmentados (Guérin et al., 2013).

La servidumbre por deuda descansa así en una compleja red de tres dimensiones: una creciente monetización de las relaciones sociales, relaciones de casta: una estructura jerárquica desigual adaptada al capitalismo, y una explotación económica y violencia caracterizadas por formas de coerción extraeconómicas. Esta servidumbre se plasma cada vez más por medio de la migración temporal y los intermediarios laborales (Srivastava, 2005; Picherit, 2009), mientras que la casta, determinada por el nacimiento y reproducida por la endogamia, añade un punto crítico a la lógica de explotación y de la internalización del dominio. Más allá de la servidumbre por deudas en sí misma, la dicotomía entre mano de obra libre y no emancipada parece poco funcional. Los trabajadores alternan labores en la agricultura, en la industria de la construcción y en industrias domésticas durante todo el año, incluidos los nueve meses de migración en calidad de trabajadores subyugados por deudas. Articulan servidumbre por deuda y trabajo eventual en un continuo de formas laborales con grados diferentes de ausencia de libertad. A decir de Lerche, una dicotomía entre mano de obra libre y no emancipada oculta la dinámica contemporánea de las relaciones laborales (Lerche, 2010). Las relaciones entre trabajadores libres y no emancipados no son algo determinado, sino dinámico y cambiante conforme a las formas del capitalismo y a las circunstancias sociales e históricas de poder (Stanziani, 2010). Lerche sostiene que la servidumbre por deuda forma parte de relaciones laborales más amplias:

\footnotetext{
la imposición de no emancipación es simplemente una de muchas maneras de controlar la mano de obra mientras se reducen los salarios por debajo de las tasas vigentes. Lejos de ser un tipo único de relación laboral, puede entenderse como una forma más o aspecto más de relaciones laborales conformadas por "la lucha de clase desde arriba bajo el neoliberalismo" [...] crean una fuerza de trabajo más dócil y barata (Lerche, 2011: 21)
}

En Mahabubnagar no existe un proceso lineal y ascendente entre formas emancipadas y no emancipadas de mano de obra. La movilidad social es 
profundamente insegura y las trayectorias sociales se mueven hacia arriba y abajo fácilmente: los mercados de trabajo se encuentran muy fragmentados según criterios de casta, religión y género y la fluidez de las relaciones laborales opera sobre todo en los segmentos más bajos de los mercados laborales, formada por los requerimientos de la industria de la construcción: una fuerza de trabajo que puede ajustarse a una base diaria, semanal o estacional. Liberar a los jornaleros y crear adhesión es un proceso dual que articula diferentes modos de dominación, economías morales y capitalistas, violencia física y simbólica. Esto da a las relaciones laborales y a la deuda formas específicas y cambiantes de acuerdo con la casta, la clase y las relaciones de género. Como destaca Bourdieu (1976), las formas en que se articulan los modos de dominación indican la manera en que se manipulan, se crean, se conciben, se representan, se negocian y se impugnan la deuda y su temporalidad.

No obstante, sólo se ha explorado una dimensión.

\section{MANO DE OBRA Y RELACIONES DE PODER EN MAHABUBNAGAR}

A partir de la década de 1930, el sistema palamur ${ }^{5}$ de servidumbre por deuda se organizó en torno a un contratista que responde a las invitaciones gubernamentales de presentarse para la construcción de canales, carreteras, presas, ferrocarriles, etc. Este contratista delega el manejo de la mano de obra en varios "grupos de maistri" que emplean a "maistris laborales" - intermediarios - en calidad de responsables de la contratación de trabajadores en el ámbito local. El grupo no excede de 40 trabajadores, mujeres y hombres (Olsen y Murthy, 2000). Endeudados y controlados por un maistri, los trabajadores migran nueve meses al año a unos tres o cinco sitios por temporada para construir presas, canales, carreteras, etc. Los maistri distribuyen adelantos en efectivo antes de la partida y supervisan la migración y el trabajo de sus respectivos grupos de trabajadores. Durante el periodo de nueve meses, los trabajadores laboran 12 horas diarias y viven en campamentos remotos. No pueden dejar el campamento libremente ni salvarse de la servidumbre mientras no salden la deuda. Madigas - casta inventariada- y Gollas ${ }^{6}$ han constituido siempre la mayoría de la fuerza de trabajo migrante en el sector de la construcción, mientras que los Reddys han sido los principales actores y beneficiarios del sistema (Picherit, 2009).

Desde los años noventa del siglo xx, la implantación de las políticas neoliberales ha transformado de manera significativa la economía y el auge de la industria de la construcción ha ofrecido posibilidades de grandes beneficios para los líderes rurales. Al mismo tiempo que mantienen su control sobre la tierra, los Reddys han reforzado sus lazos con funcionarios gubernamentales y estatales al invertir en política, la vía principal para garantizar el acceso a

\footnotetext{
${ }^{5}$ Los migrantes reciben ese nombre y se llaman a sí mismos trabajadores palamur.

${ }^{6}$ Golla es una casta de pastores clasificada por el gobierno dentro de las clases atrasadas - backward classes-.
} 


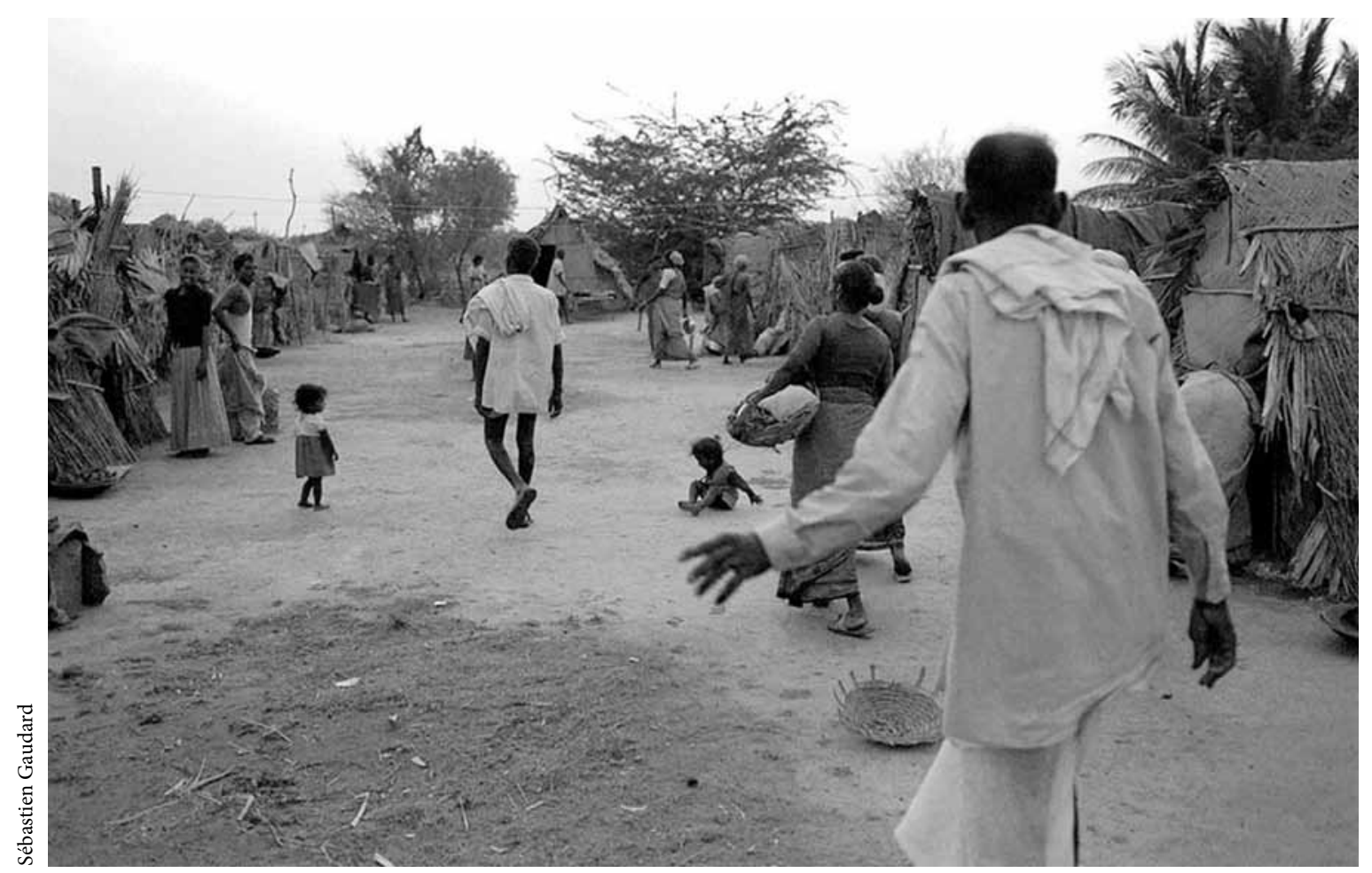

Un campo de trabajo para trabajadores atados por deudas en Andhra Pradesh.

los contratos públicos. Adquirieron maquinaria gradualmente, como camiones de volteo, que alquilan en los sitios de construcción contratados por sus compañeros de casta. Esta actividad, más lucrativa, más fácil y considerada moderna y "más limpia” que el manejo directo de la mano de obra, los animó a delegar las actividades laborales en los maistris de castas inferiores, en especial Gollas. Esto exige una proximidad directa con los trabajadores, indigna de la posición social cambiante de los Reddys:

El manejo de la mano de obra es muy duro, ipueden
quejarse por horas por un simple jabón! ¿Quién quie-
re vivir con ellos en los campamentos de trabajo?
Nadie. Preferimos rentar camiones de volteo y enviar
a los maistris a tratar ese asunto (testimonio de terra-
teniente). La politización de las castas inferiores, que hace el control de la mano de obra más difícil que en el pasado, era muy fuerte. Éste no era el final del sistema palamur o de la fortaleza de los Reddys. Más bien aceleró los modos cambiantes de dominación y de las relaciones capital-trabajo. Los Reddys eran responsables de los trabajadores de manera más directa y podían rebajar todos los costos de protección al tiempo que mantenían una fuerza de trabajo dócil. La garantía de disponer de mano de obra en situaciones específicas era crucial para cortar los costos laborales, pero también para llevarla a lugares de trabajo, como canales, canteras y presas, donde sería difícil contratar jornaleros peones a diario. Los maistris de castas inferiores, del mismo origen que los trabajadores, no gozan de suficiente peso material ni financiero para dar trabajo en los pueblos durante la temporada baja. Esto cambió la lógica de la autoridad, la movilidad social y la adhesión de los trabajadores: éstos regatean nuevos adelantos en efectivo cada año o cambian de maistri, pero pasan tres meses en el pueblo 
con escasas posibilidades de empleo en la agricultura, principalmente para las mujeres, y en el sector no agrícola.

Los Reddys conservan el control del sistema mediante el capital. Los maistris se ven obligados a entregar adelantos a los trabajadores antes del inicio de la temporada migratoria. Mientras que el maistri de grupo, de la casta Reddy, aporta la mitad del dinero, los maistri han de costear la segunda mitad de la entrega: implica una capacidad crediticia significativa. La fragmentación y discriminación en los mercados de crédito (Guérin, D’Espallier y Venkatasubramanian, 2012) permite a los Reddy controlar capital y dificultar a los maistris conseguir préstamos más altos y juntar a grupos de trabajadores más numerosos. No obstante, la neoservidumbre no responde sólo a estrategias de capital, sino a las relaciones dinámicas entre terratenientes de castas superiores, a la situación en que se encuentran los trabajadores Dalits en un contexto de politización de las castas inferiores y a una migración circular creciente de los trabajadores.

En la década de 1980 el partido regionalista Telegu Desam (TDP) surgió sobre la base de los votos de las castas inferiores. Las políticas neoliberales lanzadas por el TDP a partir de 1994, seguidas por el Congreso desde 2004, han fomentado la circulación de la mano de obra y la multiplicación de los programas antipobreza dirigidos por el Estado, las ONG y las agencias internacionales, a menudo por medio de los líderes del partido, Reddys, hasta el nivel del pueblo. El jefe del pueblo es muy claro: "No hay beneficio ni en la agricultura, ni en la mano de obra. El dinero está en la política, viene con los programas de desarrollo". Los Gollas podían acceder a la política en puestos subalternos bajo la dirección de los Reddys. Lograron asegurar un nicho en el sector de la construcción, segmentado por casta y origen geográfico, en el que son empleados como trabajadores bajo nuevas formas de dependencia. Los Gollas además tienen una fuente de orgullo local en su ocupación tradicional lucrativa como pastores y cuidadores de cabras. La politización de los Gollas, el ascenso lento de la educación y el cuestionamiento de los trabajadores a la adhesión personal fueron elementos clave en las formas emergentes de circulación, como el trabajo eventual en la industria de la construcción en Hyderabad. Empero, esas nuevas formas de circulación apenas aportan remesas suficientes y son pocos los que pueden mejorar su situación de manera significativa. Con mayor frecuencia se encuentran en el filo entre la servidumbre por deuda y el trabajo eventual (Picherit, 2012).

Salarios y posiciones inseguras, pobreza estructural y dominio de casta tornan las posiciones sociales y económicas muy precarias, hacen imperativa la búsqueda de formas múltiples y temporales de empleo, crédito y planes. Como tales, los límites entre el trabajo libre y el no emancipado se han desvanecido. Puede suceder que la mano de obra amarrada por las deudas y los jornales diarios, así como los intermediarios laborales, coexistan en la misma familia. Un trabajador amarrado por deudas labora a menudo nueve meses para un maistri, regresa y se dedica a la agricultura y/o cultiva su pequeña parcela propia - sin acceso a riego-, en tanto que se desempeña como asalariado en la construcción cuando visita a su hermano, empleado en una ciudad cercana. Desde un punto de vista diacrónico, muchos asalariados en los mercados de trabajo urbanos han laborado en calidad de mano de obra amarrada por deudas durante unos cuantos años: pueden ahorrar dinero para adquirir tierras o volver a quedarse atrapados en el sistema de servidumbre por deudas.

La diversidad creciente de medios de vida y circulación de la mano de obra mediante contratos a corto plazo, irregulares y flexibles, garantiza a los Reddys el mantenimiento de sus posiciones en las relaciones de casta y de clase. Su éxito depende de sus habilidades para articular una variedad de formas de dominio de la mano de obra y de usar maquinaria y mano de obra. El proceso dual de trabajadores libres y la neoservidumbre más bien se ha intensificado. Esas transformaciones no crearon mano de obra libre, sino jornaleros insertos en relaciones de dependencia múltiples, inseguras y eventuales. Se les 
impide acceder a protección en las ciudades y se ven obligados a trasladar sus luchas al pueblo en vez de hacerlo en sus lugares de trabajo. Esto afecta asuntos laborales, como las negociaciones personales a favor de adelantos con los maistris en el marco del sistema palamur de servidumbre por deuda, pero seguramente también asuntos de desarrollo, es decir, el intento de recibir una parte de los programas de lucha contra la pobreza. Los asuntos de protección de los trabajadores se han vuelto cruciales en la India rural. Uno de los que manipulan las ayudas con fines políticos confiesa sin rubor alguno: "Sabemos que todos regresarán de la migración a solicitar tarjetas de apoyo alimenticio y arroz, así que se las damos, ya sabes que el TDP hace mucho a favor de sus seguidores". El proceso electoral y el grueso de los programas antipobreza se ven como una oportunidad: el jefe del pueblo, un terrateniente Reddy y líder del TDP, confía en que el proceso de circulación de la economía informal le traiga de vuelta a trabajadores dependientes del acceso a los recursos estatales (Picherit, 2013a).

\section{DEUDA INTERGENERACIONAL Y LEALTAD: LA REPRODUCCIÓN DE LA SERVIDUMBRE}

Mientras la servidumbre por deuda en India cubre una amplia gama de sistemas y ha evolucionado profundamente, prevalecen muchas continuidades. Los Dalits no sólo continúan sobrerrepresentados en los rangos más bajos de la jerarquía socioeconómica (Heyer, 2010: 226): 87\% de los jornaleros amarrados por deudas pertenecen a las casas clasificadas - CC - y tribus clasificadas - TC - (NCEUS, 2009: 147). En un extremo del continuo de las relaciones laborales, algunos jornaleros están amarrados por la deuda contraída por sus padres, muertos o vivos. Este proceso es gradual, con un acento fuerte en los aspectos de casta y generacionales: sólo se ven afectados los Madigas jóvenes. Cuando llegan a una edad que fluctúa entre los diez y los 13 años y se considera que no pueden aguantar la carga de trabajo del sector de la construcción, se les deja en el pueblo a la entera disposición de los terratenientes 24 horas al día en la agricultura - ganado- y en el trabajo doméstico.

Estos Madigas jóvenes son hijos de jornaleros amarrados por deudas que alquilan a sus hijos cuando migran. Los arreglos se hacen con el terrateniente que acepta a los muchachos como si estuviera haciendo un favor a la familia: "¿quién iba a cuidar de los jóvenes?", explica uno de ellos, "tengo el deber de ayudarlos". A cambio de un crédito, el terrateniente acepta al hijo o a la hija como ayudante y se supone que debe proporcionarle alimento, cobijo, vestido y gastos de salud. Mientras que los jóvenes varones trabajan en la agricultura, las muchachas Dalits se dedican al trabajo doméstico. Cuando migraron, Daseratta y Govindamma, jornaleros atados por deudas durante 25 años y padres de cinco niñas, dejaron a su hija más joven, de nueve años de edad, confiada al jefe del pueblo. Por 1500 rupias anuales, la muchacha pasó nueve meses en la ciudad vecina, trabajando como ayuda doméstica en la familia del jefe del pueblo. A Daseratta no lo engañan con el cuento de que se trata de un favor, pero afirma que de todos modos el jefe del pueblo es el único que le ayuda. Por añadidura, podría obtener un mejor adelanto y un crédito de 6000 rupias con un interés anual de $36 \% .^{7}$ Pero todos se muestran renuentes a mencionar transacciones monetarias: la economía moral prevalece y todo el mundo prefiere aceptar que el arreglo es un favor otorgado a trabajadores específicos de confianza.

La transición agricultura/trabajo doméstico hacia la industria de la construcción inicia en torno a los 13 años de edad: esos jóvenes jornaleros entran al sistema de servidumbre por deudas y los padres reciben la mitad de un adelanto en efectivo para adultos

\footnotetext{
${ }^{7} \mathrm{El}$ interés suele expresarse como tres rupias por cada 100 prestadas, sin mención de la duración del crédito. Aquí es de 36\% anual.
} 
del maistri. La muerte de los padres constituye otra forma de entrada en la servidumbre. El maistri considera al hijo como su propiedad: "Yo les proporciono todo, no se quejan y son muy leales, no como otros". El monto de la deuda permanece oculto. Para esos jornaleros, salir de esta relación está fuera de su alcance económica y socialmente. El dominio de casta y clase se halla profundamente arraigado: convertirse en asalariados es inimaginable. Así lo expresa Shivaïah, Madiga de unos 30 años de edad:

Mi padre murió cuando tenía nueve años. Entonces migré con mi madre pero sin trabajar: preparaba té y llevaba y traía esto o aquello. Posteriormente comencé a trabajar. Tenía que comer. Ésa es mi vida, el maistri nos ofrece un adelanto y nosotros trabajamos. Mi padre había pedido prestado mucho dinero. Mis dos hijos trabajan con nosotras ahora. Sólo mi maistri Kondanna ha cambiado, fue reemplazado por su hijo (testimonio de Shivaïah).

Independientemente del monto, sólo se da importancia a las relaciones sociales y a la lealtad: la relación no se conceptualiza como una deuda o se traduce en términos financieros. Ninguna deuda puede indicar la relación entre los llamados acreedores y deudores. Todos destacan la relación generacional: se han conocido unos a otros desde el nacimiento y se hallan ligados por una relación de dominio con una deuda vigente sin un final claro. La dimensión temporal de las relaciones entre Shivaïah y Kondanna establece un dominio personal, incluidos servicios diarios, mercados de respeto y lealtad. Todo el mundo opera personalmente para mantener el estado de servidumbre.

Como lo mencioné, esta servidumbre intergeneracional se ha enrarecido. Sin embargo, el mantenimiento de lazos privilegiados y la atención prestada a la relación de confianza con un maistri continúa siendo para unos cuantos una táctica inteligente. Golla Ballaïah dedicó su vida a Mohan Reddy, uno de los maistris y terratenientes más importantes del pueblo. La relación de largo plazo entre las dos familias garantiza a Ballaïah empleo agrícola regular durante la temporada baja, una situación rara dado que los maistris no pueden dar empleo a otros jornaleros amarrados por deudas. Ballaïah es una persona de confianza del maistri-terrateniente: se encarga del grupo de jornaleros migrantes cuando el maistri se ausenta. A Balaïah le gusta recalcar su confiabilidad en comparación con los trabajadores eventuales que se van a Hyderabad. Sobreendeudado desde un punto de vista económico, el jornalero amarrado por deudas carece de la voluntad - y de la capacidad- de zanjar sus deudas. El reforzamiento del vínculo, que pugna por demostrar lealtad, prueba a Ballaïah que es una manera de protegerse a sí mismo y a su familia de formas precarias de organización del trabajo.

La combinación de deuda y su violencia económica con la obligación moral y su violencia simbólica hace ambivalente la estimación de la deuda. La precisión de una suma y una fecha de reembolso parecería una ofensa, al ser la relación interpersonal de confianza no entre individuos sino entre familias de una generación tras otra. Aun si son más bien raras, esas formas de adhesión nos ayudan a comprender los mecanismos por medio de los cuales la deuda asume diferentes significados dentro del sistema de servidumbre por deuda. Como anota Bourdieu (1976), la brecha temporal de una transacción encuentra una relación de dominación simbólica y física reforzada por las jerarquías de casta. La deuda es sólo un elemento de las relaciones sociales de poder y no puede expresar la naturaleza y el significado de la relación.

\section{DEUDA Y DIGNIDAD DE LOS JORNALEROS}

La renuencia e inhabilidad de los maistris para ofrecer protección, aunadas a vehementes búsquedas de dignidad de los jornaleros, han cambiado sustancialmente las relaciones sociales de deuda. La monetización de las relaciones ha hecho del adelanto entregado por los maistris al inicio de la temporada 
un elemento importante de negociación entre maistris y jornaleros: las condiciones de trabajo y de vida durante la migración, invariablemente las mismas, son dejadas a menudo fuera de la discusión. Pero la importancia del adelanto en efectivo no puede separarse del tema de la protección. La decadencia del patronazgo, el acceso limitado a los programas de gobierno y la escasez de empleo durante la temporada baja amplían las formas de negociación en torno a la deuda.

Tras nueve meses de trabajo en las canteras de granito, en canales, presas, edificios en construcción o carreteras, durante 12 horas diarias, los jornaleros amarrados por deudas retornan exhaustos al pueblo y con escasa idea sobre el monto de la deuda pendiente con los maistris. Durante la temporada migratoria, el maistri suma todos los gastos — jabón, alcohol, cigarrillos y otros - a la deuda del jornalero: es el único que sabe escribir, llevar un libro de registro y con harta frecuencia significa que han de recurrir a otro adelanto y a trabajar en lo mismo de nuevo.

La temporada baja parece ser un periodo clave en la reproducción de la servidumbre. Los jornaleros han de financiar esos tres meses con escasas oportunidades de empleo. Mientras que algunos tienen posibilidades de desplazarse como mano de obra temporal a las ciudades cercanas, muchos permanecen en el pueblo y trabajan de vez en cuando en las propiedades agrícolas de los terratenientes. Contraer nuevas deudas para costear este periodo de desempleo es normal. El adelanto entregado por los maistris antes de la partida ya ha sido gastado para entonces: los trabajadores se vieron obligados a pedir prestado una y otra vez a los maistris durante el periodo migratorio.

Si bien este círculo atrapa a los jornaleros en la servidumbre y los obliga a negociar un nuevo adelanto cada año, no están atados ya a un único maistri. La disminución de las adhesiones personalizadas y la afirmación creciente de los jornaleros de castas inferiores los faculta para cambiar de maistri. Esto representa una táctica importante para que los jornaleros afirmen su dignidad: todos pujan por adelantos de mayor envergadura. Si la dignidad es esencial, el poder de negociación de los jornaleros es muy limitado, los maistri se conocen entre ellos y elaboran listas negras. No obstante, los trabajadores destacan que la posibilidad de negociar es una ventaja contra maistris y patrones. Esto no rompe con el sistema de servidumbre, pero los jornaleros "la van pasando" dentro del sistema y las condiciones de trabajo son muy similares independientemente del maistri.

Una vez que se entrega el adelanto, rara vez surgen cuestionamientos: los jornaleros se comprometen a seguir al maistri, cualquier resistencia a los maistris se pospone y el cambio de maistri se convierte en una cuestión de disciplina: "No voy a trabajar con él la temporada próxima. Me iré con Chadraïah. Él [actual maistri] no da nada, el campamento de trabajo está sucio y grita todo el tiempo. Chadraïah ofrece buenos adelantos y mi cuñado ya ha trabajado con él", explica Madiga Ramallu. Empero, Kushema no se engaña: "El nuevo maistri sonríe, ofrece dinero, pero la vida es siempre la misma. Trabajar, comer, dormir...”.

La deuda es el cuento de nunca acabar: circula entre los maistris. El sistema conserva la mano de trabajo dentro de sus límites: la deuda permanece en el pueblo, el centro de circulación de la mano de obra y de las relaciones de poder. Muchas situaciones complejas asocian la negativa de dependencia personalizada con la servidumbre por deudas y otras formas de trabajo. Es el caso de Golla Daseratta en el pueblo: "Voy a donde quiero: trabajé duro y el maistri no me da nuevos adelantos. ¡Construí canales, carreteras, presas! No necesito maistri alguno. Su comida es repugnante y sus campamentos están sucios. Me voy a Hyderabad. Ya trabajé allä".

Dos meses más tarde, Daseratta trabajaba para un nuevo intermediario laboral en la construcción de un canal, pero se fue del campamento para reunirse con sus dos hijas casadas establecidas en Hyderabad, a donde migran los jornaleros de su casta, Golla, y encuentran empleo diario en la construcción. Luego regresó al pueblo y los miembros de su casta lo 
obligaron a retomar el trabajo del canal: debe respetar el arreglo y la deuda. De vuelta en el pueblo después de la temporada, Daseratta trabaja en forma irregular para un terrateniente Reddy. Al mismo tiempo, negocia con otro maistri: el primero se negó a darle un adelanto más. De nuevo se va a trabajar nueve meses.

Jornalero amarrado por deudas durante los últimos 30 años, Daseratta fue también cabrero, ayudante de peón, jornalero eventual, trabajador agrícola, labores que siempre combinó con la servidumbre por deuda. El deseo de escapar de la servidumbre por deuda, aun la negociación de estas relaciones - "voy a donde quiero, siempre que quiera" - , se ve matizado por una afirmación recurrente de los jornaleros en esta situación: "vamos a donde nos manda el maistri". El cambiante sistema de servidumbre por deudas palamur es un instrumento poderoso para subyugar la mano de obra mediante deudas y migración. La falta de protección de los maistris y la necesidad absoluta de descanso físico tras las condiciones de vida y trabajo extremas durante la mi-

gración vuelven la temporada baja un periodo para la reproducción de la mano de obra, cuyo costo asumen los mismos trabajadores. El descanso y/o desempleo son periodos de creciente endeudamiento, financiado por los futuros adelantos esperados, que reduce en forma considerable la posición negociadora de los migrantes potenciales. Además, su ausencia del pueblo los excluye del grueso de los programas de lucha contra la pobreza del gobierno, dado que exigen tiempo, servicios gratuitos y deferencia ante los que están encargados de los programas. Los jornaleros amarrados por deudas no obtienen más que migajas. Esos jornaleros no salen de este sistema de servidumbre y el endeudamiento está totalmente integrado a las relaciones de poder, que constantemente son negociadas, resistidas o aceptadas. La deuda está entonces en el meollo de las relaciones sociales de poder, dado que no existen otras formas de protección o asuntos qué negociar.

\section{EN ESPERA DE LA CAÍDA}

Las formas de neoservidumbre apenas pueden separarse de otras relaciones laborales. Como en el caso de Daseratta, que trabaja de vez en cuando como jornalero en Hyderabad durante la temporada baja, la alternancia entre mano de obra libre y no emancipada apenas es operativa en el caso de los trabajadores que se encuentran al filo de la navaja. Lerche (2011) pone en entredicho los argumentos de Breman y Brass de que, a pesar de ser compatible con el capitalismo, la servidumbre por deudas es única en términos de formas extraeconómicas de coerción. De hecho, es común que existan diferentes grados de coerción económica en la economía informal, en la que la segmentación de los mercados laborales urbanos de la India, con las líneas de casta y geográficas, es fuerte.

Los jornaleros Gollas de Peddapur sólo pueden acceder a un vecindario en Hyderabad a través de la mediación de compañeros de casta. El mercado de trabajo local es un nicho en el que sólo Gollas originarios del distrito de Mahabubnagar son captados para trabajar como mano de obra con jornal diario en el sector urbano de la construcción. Este nicho es crucial para los Gollas y sus posiciones económicas y sociales en el pueblo. Los maistris de otras castas los ayudan al llegar y les facilitan un jacal, acceso a agua y crédito de los abarroteros. A diario los reúnen en un lugar al que los maistris llevan entre diez y 15 jornaleros a trabajar en un edificio. No hay garantía de trabajo y se está obligado a complacer a los maistris para tener empleo a diario. Los llamados trabajadores libres son enteramente dependientes del maistri: cualquier incidente o conflicto en el lugar de trabajo y en el vecindario ponen su situación en riesgo. Además, otros Gollas se esmeran en evitar problemas para conservar el acceso a este mercado: el nicho tiene que ser conservado y ellos son sólo jornaleros.

Las diferenciaciones internas dentro de la casta van en aumento con las cambiantes relaciones laborales y políticas, y las situaciones de los jornaleros 
Gollas en el mercado de trabajo pueden diferir radicalmente. El grupo de Gollas llevado por el maistri - no más de 15- puede incluir a un Golla que es propietario de una pequeña parcela y algunas cabras, necesitado de dinero en efectivo, y a otro que solía ser mano de obra amarrada por deudas pero que logró negociar su deuda con el maistri. Para el segundo el riesgo de recaer en la servidumbre es elevado. La relación entre trabajo eventual y servidumbre por deuda puede sobrevenir también por cálculos familiares al considerarse un adelanto en efectivo un préstamo sin interés: un hijo puede conseguir un adelanto sustancial y reembolsarlo en trabajo, mientras sus hermanos pueden ser jornaleros agrícolas o asalariados. En este caso, toman el adelanto y el hermano que se emplea como jornalero eventual puede ayudar a pagar la deuda con el maistri. Esta entrada a la servidumbre, degradante en términos de posición social, se lleva a cabo haciendo malabarismos con las deudas y a partir de una menor subordinación: "la van pasando".

Pero cualquier fracaso en la migración, un asunto de salud o una serie de incidentes puede debilitar fácilmente las situaciones precarias y conducir a la migración con un maistri. El proceso no es lineal entre mano de obra libre y no emancipada: los jornaleros eventuales que necesitan una suma importante de dinero, para una dote, boda o algún otro gasto social, cuentan con un solo maistri para conseguir un adelanto cuantioso de dinero en efectivo. Las historias de éxito son raras: la movilidad social es insegura y muchos retornan a la servidumbre por deudas (Picherit, 2012). Chadraïah y Kushnamma son Gollas. Cuandolos conocí, eran propietarios de una parcela de varios acres, un pequeño rebaño de cabras y dos búfalos. Los dos hijos estudiaban, un orgullo para sus padres, que durante años fueron jornaleros amarrados por deudas: "En esa época no sabíamos cómo conseguir un préstamo. Pero nuestros maistris fallecieron e invertimos algún dinero en un primer y exitoso pozo de bombeo". Poco a poco adquirieron cabras, cuyo cuidado es una ocupación tradicional de su casta e inveteradamente la principal fuente de prestigio, mientras iban de vez en cuando a Hyderabad como trabajadores eventuales. Su movilidad social representó un ejemplo de éxito... y suerte. La educación de los hijos era una señal clara de su nueva posición social. Empero, la situación no dejaba de ser precaria:

También tenemos dos búfalos... y cuatro acres de tierra. Disponíamos de tres pozos, el primero duró dos años, el segundo tres años y el último tiene poca agua. Un pozo nuevo cuesta mucho dinero. También estoy trabajando como jornalero agrícola mientras Chadraïah cuida las cabras y laboro un poco en el campo (testimonio Kushnamma).

Kushnamma estaba preocupado por la situación presente y trataba de hacer verdaderos malabarismos con las deudas con varias personas: "Gastamos unas 60000 rupias en maíz pero está echado a perder. Pedimos dinero prestado para comprar algunas cabras y para la casa. Los préstamos son privados". Con "privados" Kushnamma quiere decir que provienen de personas conocidas y con buena fama pública, que sólo prestan a gente recomendada con algún tipo de garantía: "Fuimos a ver a una persona muy conocida, pero son gente peligrosa. Si nos les pagamos la deuda, hablarán mal de nosotros. Son Reddy, tienen todo el dinero". Otro préstamo es del Banco Gubernamental de Kothakotta: "Eso fue para el pozo y la bomba. Lo solicitamos hace siete años". Para este tipo de préstamo se hipoteca la tierra. Si el banco extiende los pagos de reembolso, el "privado" - telisinimanisi- envía matones y no duda en tratar con brutalidad a los clientes con el fin de recuperar el dinero.

Los significados de la deuda han cambiado con las posibilidades ofrecidas por los mercados de crédito. La deuda es para ser reembolsada y la violencia de los cobradores aumentó drásticamente. Esto afecta a los prestamistas, pero también a las instituciones de microfinanciamiento y a las organizaciones de microcrédito que estaban orgullosas y bajo presión para acercarse al 100\% del cobro de los reembolsos (Picherit, 2013b). Chandraïah falleció pocos 
meses después. La situación cambió de manera dramática. La muerte representa el punto de partida de la decadencia de la familia: cualquier accidente o problema de salud puede arruinar años de lucha. La deuda se convirtió en un peso y el endeudamiento devino en sobreendeudamiento. No hay red de seguridad, la protección a largo plazo no existe. La decadencia de la familia está ligada a la obligación social de pagar la deuda, en términos de honor.

Durante años, lograron vivir por sí mismos sin depender enteramente del maistri o de un terrateniente de casta superior. Para esta familia previamente amarrada por deudas, el ascenso social se simbolizaba en la educación del hijo y de la hija. Su posición social en el pueblo había cambiado, habían ganado cierto respeto entre sus congéneres de casta, mostraron a todo el mundo la inversión hecha en educación, su hijo era uno de los pocos que estudiaban a ese nivel. La tierra fue usada como garantía para proyectarse en el futuro cercano y conseguir créditos. El rebaño se desplegaba en torno a la casa

a últimas horas de la tarde y Chadraïah disfrutaba dar la vuelta a los campos con los propietarios de la tierra y de los rebaños. Muy pronto, su hijo de 16 años tuvo que dejar la escuela para conseguir trabajo: carecía de conocimientos de agricultura y sólo podía ser "ayudante" en una construcción con un maistri. Unos meses después se vio obligado a aceptar un adelanto de un maistri, la única opción para conseguir una buena suma de dinero: significaba un compromiso de por lo menos cuatro años de trabajo.

$\mathrm{El}$ ascenso social se esfumó para esta familia. El futuro del hijo se hallaba en entredicho, la educación se evaporó y tuvo que comenzar a trabajar en una construcción como mano de obra atada por deudas para pagarlas. Esto bosqueja las líneas entre la posición social de los jornaleros en un contexto de inseguridad permanente: la muerte, la enfermedad, los accidentes de trabajo, la sequía recuerdan a estos Gollas lo precario de su situación. Las deudas contraídas por la familia eran parte de las relaciones económicas con personas bien conocidas y con el banco. Su movilidad social los animaba a exhibir su éxito y su recién adquirida posición social. Si las presiones económicas eran fuertes para pagar las deudas, representaban asimismo una cuestión de respetabilidad en el pueblo. La decadencia de la familia está ligada a la obligación social de cubrir la deuda. Durante años Chadraïah gozó su movilidad y orgullo, ligados a su historia de servidumbre por deuda, que descansaban en cortar la dependencia, una táctica riesgosa pero exitosa hasta el día de su muerte. Las múltiples jerarquías son reforzadas por los jornaleros de casta inferior ansiosos por acentuar su movilidad social ascendente al mantener a otros por debajo de ellos: el retorno a la servidumbre por deudas conduce a una enorme pérdida de prestigio, pero al mismo tiempo mantiene la capacidad de crédito de la familia y la dignidad propia (Guérin et al., 2013).

El sobreendeudamiento aparece cuando las deudas tienen que ser pagadas, cuando las posibilidades de hacer malabarismos con éstas se agotaron y cuando se asocian con un descenso de la posición social y el prestigio: el mantenimiento del buen nombre es crucial, un bien para el futuro. La decadencia no significa únicamente pérdida de dinero, sino un fracaso para los planes futuros, el ascenso social, las perspectivas y las expectativas. Significa perder cara tras años de éxito y a veces de garvam -orgullo y arrogancia - hacia antiguos compañeros de trabajo.

\section{CÓMO HACER DE LOS JORNALEROS GENTE DESPROTEGIDA Y ENDEUDADA}

El panorama de la protección ha cambiado profundamente en los últimos 15 años. A partir de 1990, los programas de desarrollo focalizados en categorías específicas de población - casta, edad, género- han sido operados en buena medida a través del principal partido político. La mayoría de los programas de desarrollo estatales o de las ONG están enraizados en estructuras locales de acumulación económica y/o política manejadas por diferentes tipos de "hombres 
fuertes" (Price y Ruud, 2010) y "de porteros que abren o cierran puertas” (Pattenden, 2011). El acceso a esos programas representa enormes inversiones para los trabajadores atados por deudas, alejados de sus pueblos durante nueve meses del año. Negociar la obtención de agua, arroz, cuidados de salud, dinero en efectivo, crédito, trabajos, servicios estatales, programas de ong y ayuda de las organizaciones de desarrollo implica vérselas con el intermediario político. Se trata de una figura clave en la vida cotidiana de los jornaleros, que rara vez se encuentran con funcionarios o líderes rurales en persona.

N. Reddy era el funcionario al frente del desarrollo del pueblo y estaba encargado de recaudar el dinero de los grupos de microcrédito en el nivel del Cluster Mandal. El Cluster estaba encabezado por su abuela y su madre era la principal prestamista del pueblo. Él era el responsable de movilizar a los seguidores durante los mítines políticos y de organizar las manifestaciones de poder del TDP en el curso de los festivales religiosos del pueblo. Solía acudir a muchos lugares a cobrar los préstamos a los migrantes. Trataba con las castas inferiores, las apoyaba en la vida cotidiana, al tiempo que utilizaba la violencia para mantenerlas bajo control por ser cercano y distante de ellas, y usaba sus habilidades para dividir, individualizar o unir a las personas según las circunstancias. Pero, sobre todo, se aseguraba de que todos votaran por el TDP por medio de su control de la protección de los pobres: jugaba sutilmente la carta de la casta, la clase, el género y las identidades al redistribuir los recursos. N. Reddy se ha beneficiado en particular de los programas de combate a la pobreza y de desarrollo, también ha acaparado muchos de los negocios emergentes para los pobres en las áreas rurales, se vale de su poder para vender

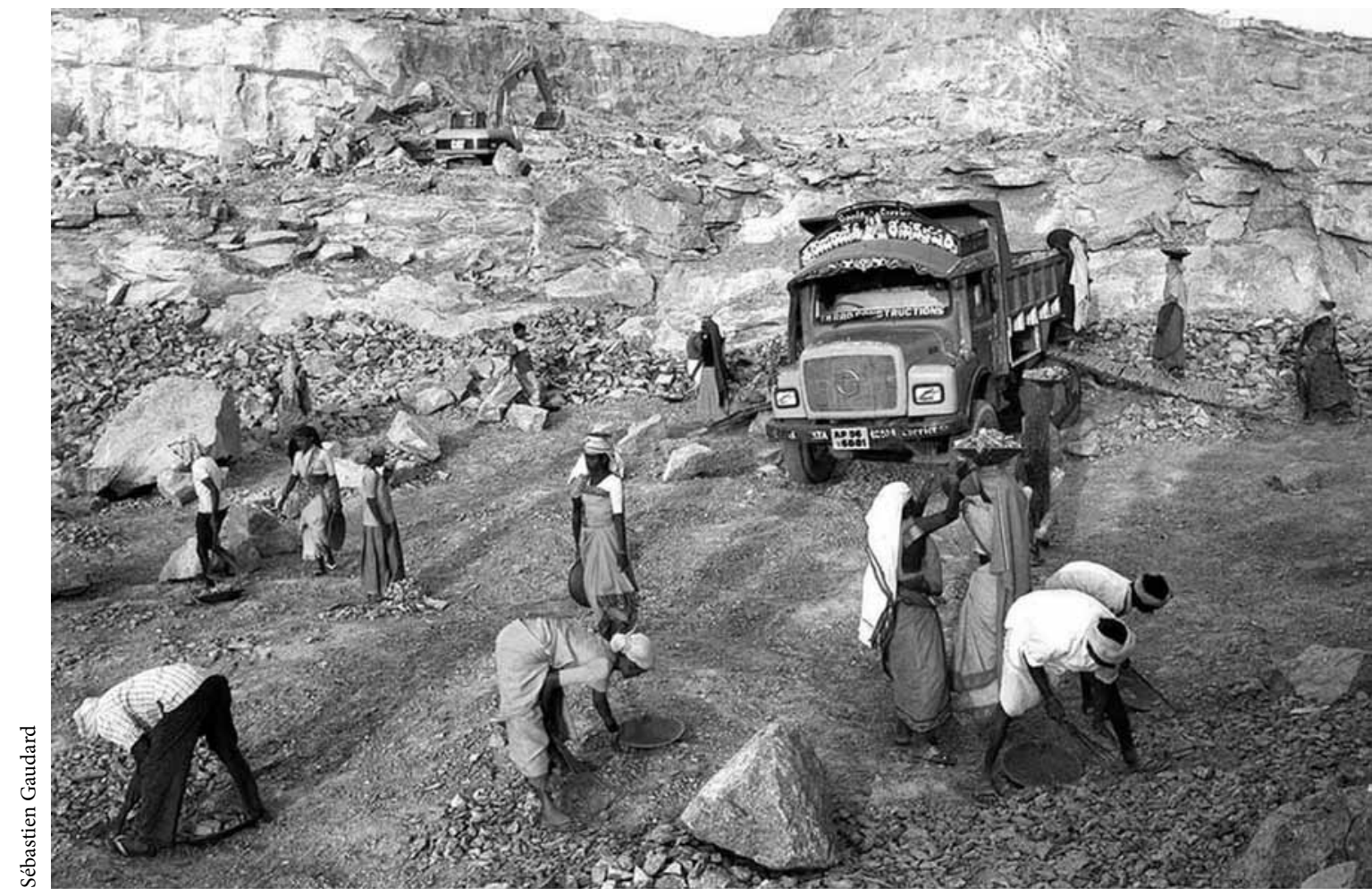

Trabajadores en la mina de piedra, Andhra Pradesh. 
productos subsidiados que le son entregados para ayudar a la gente. En los últimos cinco años construyó una nueva casa, adquirió una motocicleta, inscribió a sus dos hijos en la secundaria inglesa de la ciudad cercana y compró dos teléfonos celulares "por onda". Confiesa lleno de orgullo:

Tenemos que asegurarnos los votos si queremos dinero para el desarrollo. Si no hay voto, no hay desarrollo, ni dinero, ni trabajos. Me pusieron a cargo de los contratos para NREGA [National Rural Employment Guarantee Act] y me dan buenas comisiones. También estoy encargado de los materiales subsidiados que vendo. Vendí 163 conexiones de TV por cable y seguros de vida. La gente sabe que tengo contactos y recibo 10 o 20\% de comisión. Ahora me respetan (testimonio N. Reddy).

El despliegue de su influencia, éxito y poder, la apariencia de estar bien conectado y ser cercano a los poderosos es su trabajo. N. Reddy es el hombre influyente con quien los jornaleros han de negociar

Sayamma, jornalera Madiga amarrada por deudas, intenta tener acceso a los programas por todos los medios a su alcance, aun desde el campamento de trabajo. Pero eso a menudo significa una doble dependencia y carga extra, en particular para los trabajadores amarrados por deudas, que no tienen autorizado regresar al pueblo para arreglar esos asuntos. Hacerse unas fotos de credencial significó trabajar más duro en el sitio de migración para obtener la buena voluntad del maistri. Tuvo que esperar hasta tener un día libre para desplazarse a la ciudad cercana, recibir la aprobación de su esposo y del maistri, conseguir dinero para el transporte y las fotografías, etc. Es una lucha interminable que a cada paso exige - en el mejor de los casos- visitas, cumplimiento y deferencia con el maistri; en el peor escenario, también le pueden solicitar servicios sexuales. Esta rutina, una táctica de temor y desánimo, tiene continuidad en el pueblo. N. Reddy espera deferencia, presencia y disponibilidad durante tres semanas.

El maistri es descartado como fuente de apoyo para acceder a los beneficios del desarrollo. No estaría preparado para interferir en los negocios de los intermediarios políticos de la casta superior. Además, Sayamma no tiene otros apoyos en el pueblo y sólo puede contar con ese tipo de intermediario. La política requiere una presencia regular, pero el sistema migratorio impide cualquier organización eficiente de los Madigas. Sólo los ancianos permanecen en el pueblo. La comparación de la situación de los Madigas con la de los Gollas aclara el asunto. Los Gollas pueden retornar regularmente de Hyderabad cuando es necesario - las fotos de credencial no serían un problema- y confían en los compañeros de casta que tienen bienes y son influyentes en la política. Incluso los jornaleros Gollas maniatados por las deudas tienen, por limitado que sea, apoyo de casta. Es más, dada la forma en que están organizados los programas de desarrollo y la rutina de violencia y pobreza, no sólo usan la explotación y la dependencia como una forma "normativa" de negociar, sino también disuaden de cualquier intento de cambiar la manera en que funcionan las cosas. El tiempo, el trabajo y la energía requeridos se han convertido en un peso adicional, sobre todo para las mujeres categorizadas por el grueso de los programas como confiables y agentes dóciles del cambio. Durante la temporada baja trabajan en la agricultura y desempeñan tareas reservadas casi enteramente a las mujeres (Da Corta y Venkateshwarlu, 1999), reciben la mitad del salario de los hombres, realizan labores domésticas y se encargan de los programas de desarrollo.

Los Madigas saben bien cómo emplear la deferencia de una manera pragmática (Still, 2011). No obstante, en estas circunstancias de pobreza y de relaciones muy desiguales se ven obligados a cumplir los dictados de los poderosos y de trabajar sin remuneración. Cuando Venkata, un jornalero amarrado por deudas, regresó de la migración, se puso a disposición de un terrateniente Reddy durante tres días con el fin de pedirle prestadas 150 rupias. 
Cargó pesados sacos de arroz de un lado a otro, acarreó comida de la tienda y limpió afuera de la casa para obligar al terrateniente a prestarle dicha cantidad de dinero, una pequeña deuda que tendría que cubrir de su futuro adelanto con un maistri. Se trata de una forma temporal de dependencia: tan pronto como obtiene el efectivo, Venkata deja de ir y reproduce la misma táctica con otro terrateniente. Su esposa, Kushnemma, se centró en la organización de un grupo de microcrédito para conseguir un pequeño préstamo destinado a los gastos cotidianos. Tras una larga ausencia de su marido, tuvo que convencer a otras mujeres de su capacidad de crédito, participar en las reuniones del grupo de autoayuda y desempeñar todas las tareas de servicio relacionadas con el grupo - cargar los libros, lavar platos usados durante las reuniones y demás-. Pero se vio obligada a pedir a N. Reddy que la apoyara. A menudo éste emplea su influencia para amenazar o influir en el funcionamiento cotidiano del microcrédito. $\mathrm{Al}$ encargarse de visitar los pueblos para los programas de microcrédito, mantiene una política de temor a través de la arbitrariedad, la violencia simbólica, la amistad y la exigencia de favores sexuales.

El trabajo y los servicios no remunerados forman parte de la "participación" necesaria para beneficiarse de los programas de combate a la pobreza. $\mathrm{N}$. Reddy individualiza, juega y redistribuye según diversas jerarquías locales micro y recrea dependencias que son temporales y múltiples: casta y clase son categorías movilizadas y abandonadas de acuerdo con el contenido por intermediarios y trabajadores por igual. Sin embargo, su tendencia a la violencia le impide a N. Reddy estar al servicio de los trabajadores. Este panorama apunta a los cambios que suceden en el ámbito local. Para otros jornaleros Madigas amarrados por deudas, trabajadores eventuales o autoempleados, esta situación no es sostenible. Los migrantes amarrados por deudas son, sin duda, los últimos en la línea de redistribución de recursos para el desarrollo y reciben sólo las migajas de cualquier programa. Ningún Madiga se ha convertido en intermediario y carecen de posibilidad de obtener alguna "ventaja" significativa sobre otros o de escapar de la pobreza. Todos se benefician marginalmente de los programas, pero nunca como un derecho. Si sus condiciones absolutas han mejorado con los años, su posición relativa en el pueblo permanece inmutable.

\section{CONCLUSIONES}

Este artículo muestra que la monetización de las relaciones laborales, aunada a la reconfiguración de la protección, recrea formas múltiples y temporales de coerción y de dependencia en las relaciones laborales eventuales y de servidumbre por deudas. Las relaciones sociales de deuda han evolucionado profundamente con los modos de dominación articulados por los terratenientes-contratistas-políticos en el campo del sur de la India. El control sobre los recursos del Estado es crucial en la manipulación de las relaciones sociales de poder y del lugar que ocupa el endeudamiento en el control sobre la mano de obra. Los Reddys han aprovechado las instituciones sociales y políticas, sus mecanismos y sus reglas para acaparar contratos en la industria de la construcción, pero también los principales programas asignados a los etiquetados como "pobres". Esto los vuelve muy confiados en la economía informal para crear dependencia de los trabajadores, imposibilitados de encontrar protección en las áreas urbanas, y también para aflojar los lazos de la servidumbre por deudas. Como notó Bourdieu (1976: 125-126), la dominación personal cuesta tiempo y energía, y exige trabajar todos los días para asegurar la confianza $y$ hacer que las relaciones de patronazgo parezcan morales. Este dominio personal parecería haber llegado a su fin, pero los patrones tienen suficiente control sobre las instituciones para delegar el manejo de la mano de obra en maistris de castas inferiores, mientras que los trabajadores eventuales regresan al pueblo en búsqueda de protección.

No existen distinciones claras entre esquemas de trabajo y modos de dominación (Lerche, 2011). En 
el mejor de los casos los Reddys articulan formas de poder y economía según las circunstancias. Otorgan a las deudas diferentes significados en relación con las maneras en que se hallan organizados los mercados de trabajo, juegan alternativamente con la confianza y la violencia, atraen y rechazan la mano de obra conforme a sus requerimientos. Esos modos articulados de dominación y el aflojamiento de los lazos crean las condiciones para el sobreendeudamiento. La obligación moral y violenta de reintegrar el préstamo, con prestamistas externos, matones y ausencia de protección confiable transforma la deuda en sobreendeudamiento.

Esas combinaciones de las diversas modalidades de dominación y poder han abierto espacios enormes de negociación, manipulación, resistencia y ajuste para los trabajadores. Los jornaleros no se engañan y su búsqueda de protección, en contraste con una adhesión personalizada, implica tácticas para conseguir créditos, trabajos y programas. Hacen malabarismos con las deudas, juegan con las relacio-

nes sociales y utilizan la confianza, la esperanza y los servicios en los asuntos cotidianos. La deuda no está separada sino que parte de un conjunto más amplio de transacciones, como servicios, trabajo libre, respeto otorgado o añadido a las relaciones. Como señala Villarreal: "en las transacciones financieras, los valores y las transacciones monetarias y no monetarias se hallan entrelazadas" (Villarreal, 2013: 60) y la monetización es un proceso con grados que varían según las circunstancias de las relaciones sociales y de poder.

Contrario a lo que sucede en otros contextos (Guérin, Morvant-Roux y Villarreal, 2013), la limitada capacidad de acción de los trabajadores en situaciones tan extremas los inhabilita para sacar ventaja de la deuda salvo en los márgenes, al tiempo que los maistris son los únicos que les dan adelantos en efectivo. El maistri es la única persona confiable, dispuesta a entregarles una suma enorme en comparación con los prestamistas y otras fuentes. El adelanto es insuficiente y los trabajadores buscan acceder a los programas de gobierno, cuando están al tanto de su disponibilidad. No obstante, el Estado "posee el poder de hacer cumplir las leyes, [pero] de hecho opta por no hacerlo" (Harriss-White, 2010: 144). La redistribución de los programas estatales con financiamiento público es un proceso de reformulación y reafirmación de microjerarquías de casta, clase, generación, familia y género, entre solidaridades y divisiones según el contexto de las relaciones de poder locales. El proceso de redistribución mantiene la dinámica y las tensiones inestables de las relaciones de poder cotidianas, para forzar la dependencia de los trabajadores, conformar los modos de negociación y convertir la deuda en un elemento clave de manipulación y negociación de los trabajadores. Los trabajadores amarrados por deudas y en su calidad de eventuales no sólo son explotados mediante las relaciones laborales, también son excluidos en diversos grados de la redistribución del dinero público, por lo que el endeudamiento es la única posibilidad para cubrir los gastos básicos.

\section{BIBLIOGRAFÍA}

Behal, Rana P. y Marcel van der Linden (eds.), 2007, India's Labouring Poor: Historical Studies c. 1600-c. 2000, Cambridge University Press, Nueva Delhi.

Bloch, Maurice y Jonathan Parry, 1989, Money and Morality of Exchange, Cambridge University Press, Cambridge.

Bourdieu, Pierre, 1976, "Les Modes de Domination", en Actes de la Recherche en Sciences Sociales, núms. 2-3, pp. 122-132.

Brass, Tom, 1990, "Class Struggle and Deproletarianisation of Agricultural Labour in Haryana (India)", en Journal of Peasant Studies, vol. 18, núm. 1, pp. 36-67.

_ 1994, "Contextualizing Sugar Production in Nineteenth Century Queensland", en Slavery and Abolition, vol. 15, núm. 1 .

, 1999, Towards a Comparative Political Economy of Unfree Labour: Case Studies and Debates, Frank Cass, Londres.

Breman, Jan, 1996, Footloose Labour: Working in the Indian Informal Economy, Cambridge University Press, Cambridge.

, 2007, The Poverty Regime in Village India: Half a Century of Work and Life at the Bottom of the Rural 
Economy in South Gujarat, Oxford University Press, Nueva Delhi.

— Isabelle Guérin y Aseem Prakash (eds.), 2009, India's Unfree Workforce: Old and New Practices of Labour Bondage, Oxford University Press, Nueva Delhi.

Carswell, Grace y Geert de Neve, 2013, "From Field to Factory: Tracing Transformations in Bonded Labour in the Tiruppur Region, South India”, en Economy and Society, vol. 42, núm. 3, pp. 430-454.

Da Corta, Lucia y Davuluri Venkateshwarlu, 1999, "Unfree Relations and the Feminisation of Agricultural Labour in Andhra Pradesh, 1970-1995", en Terence Byres, Karin Kapadia y Jens Lerche (eds.), Rural Labour Relations in India, India Research Press, Nueva Delhi, pp. 71-139.

De Neve, Geert, 1999, “Asking for and Giving Baki: Neobondage, or the Interaction of Bondage and Resistance in the Tamilnadu Power-loom Industry", en Contributions to Indian Sociology, vol. 3, núms. 1 y 2, pp. 379-406.

Elyachar, Julia, 2002, "Empowerment Money: The World Bank, Non-Governmental Organizations, and the Value of Culture in Egypt", en Public Culture, vol. 4, núm. 3, pp. 493-513.

Guérin, Isabelle, 2013, "Bonded Labour, Agrarian Changes and Capitalism: Emerging Patterns in South India", en Journal of Agrarian Change, vol. 13, núm. 3, pp. 405-423.

—, Bert d'Espallier y Govindan Venkatasubramanian, 2012, "Debt in Rural South India: Fragmentation, Social Regulation and Discrimination", en Journal of Development Studies, pp. 1-17.

_ Solène Morvant-Roux y Magdalena Villarreal (eds.), 2013, Microfinance, Debt and Over-Indebtedness. Juggling with Money, Routledge, Londres.

- et al., 2013, "The Social Meaning of Over-Indebtedness and Creditworthiness in the Context of Poor Rural South Indian Households (Tamil Nadu)", en Isabelle Guérin, Solène Morvant-Roux y Magdalena Villarreal (eds.), Microfinance, Debt and Over-Indebtedness. Juggling with Money, Routledge, Londres, pp. 125-150.

Harriss-White, Barbara, 2003, Indian Working: Essays on Economy and Society, Cambridge University Press, Londres.

_ 2010, "Globalization, the Financial Crisis and Petty Production in India's Socially Regulated Informal Economy", en Global Labour Journal, en línea: $<$ http://digitalcommons.mcmaster.ca/globallabour/ vol1/iss1/9>.

Heyer, Judith, 2010, “The Marginalisation of Dalits in a Modernising Economy”, en Barbara Harriss-White y
Judith Heyer (eds.), The Comparative Political Economy of Development: Africa and South Asia, Routledge, Londres, pp. 225-247.

Kapadian, Karin, 1995 "The Profitability of Bonded Labour: The Gem Cutting Industry of Rural South India”, en The Journal of Peasant Studies, vol. 23, núm. 3, pp. 446-483

Lerche, Jens, 2007, "A Global Alliance against Forced Labour? Unfree Labour, Neo-Liberal Globalization and the International Labour Organization", en Journal of Agrarian Change, vol. 7, núm. 4, pp. 425-452.

_ 2010, "From Rural Labour to Classes of Labour: Class Fragmentation, Caste and Class Struggle at the Bottom of the Indian Labour Hierarchy”, en Barbara Harriss-White y Judith Heyer (eds.), The Comparative Political Economy of Development, Routledge, Londres, pp. 64-86.

, 2011, “The Unfree Labour Category and Unfree Labour Estimates: A Continuum within Low-end Labour Relations", en Manchester Papers in Political Economy, en línea: <http://www.socialsciences.manchester. ac.uk/PEI/publications/wp/documents/Lercheunfreeworkingpaper.pdf $>$.

Michelutti, Lucia, 2008, The Vernacularisation of Democracy: Politics, Caste, and Religion in India, Routledge, Nueva Delhi.

National Commission for Enterprises in the Unorganised Sector (NCEUs), 2009, The Challenge of Employment in India: An Informal Economy Perspective, National Commission for Enterprises in the Unorganised Sector, vol. 1, Nueva Delhi.

Olsen, Wendy y Ramana Murthy, 2000, "Contract Labour and Bondage in Andhra Pradesh (India)", en Journal of Social and Political Thought, en línea: <http://www. yorku.ca/jspot/2/wkolsenrvramana.htm >.

Parry, Jonathan y Maurice Bloch, 1989, Money and the Morality of Exchange, Cambridge University Press, Nueva York.

Pattenden, Jonathan, 2011, "Gatekeeping as Accumulation and Domination: Decentralisation and Class Relations in Rural South India”, en Journal of Agrarian Change, vol. 11, núm, 2, pp. 164-194.

Picherit, David, 2009, “'Workers, Trust Us!': Labour Middlemen and the Rise of the Lower Castes in Andhra Pradesh", en Jan Breman, Isabelle Guérin y Aseem Prakash (eds.), India's Unfree Workforce: Old and New Practices of Labour Bondage, Oxford University Press, Nueva Delhi, pp. 259-283.

, 2012, “Migrant Labourers' Struggles between Village and Urban Migration Sites: Labour Standards, Rural Development and Politics in South India”, en 
Global Labour Journal, en línea: <http://digitalcommons.mcmaster.ca/globallabour/vol3/iss1/7>.

, 2013a, "Neither a Dog nor a Beggar: Seasonal Labour Migration, Development and Poverty in Andhra Pradesh", en Nandini Gooptu y Jonathan Parry (eds.), The Persistence of Poverty in India, Social Sciences Press, Nueva Delhi.

, 2013b, "The End of Microfinance in Andhra Pradesh? Politics and the Neoliberal Model of Development", en Microfinance in crisis, Research and Policy Briefs, en línea: <http://www.microfinance-in-crisis. org/wp-content/uploads/Research-and-PolicyBrief_4.pdf $>$.

Price, Pamela y Arild Engelsen Ruud, 2010, Power and Influence in India. Bosses, Lords and Captains, Routledge, Nueva Delhi.
Srivastava, Ravi, 2005, "Bonded Labour in India: Its Incidence and Pattern”, Organización Internacional del Trabajo, Ginebra.

Stanziani, Alessandro (ed.), 2010, Le Travail Contraint en Asie et en Europe, XVII-XX Siècles, Maison des Sciences de l'Homme, París.

Still, Clarinda, 2011, "The State in the Palli: Dalit Perspectives on the State in Andhra Pradesh", en Contemporary South Asia, vol. 19, núm. 3, pp. 315-329.

Villarreal, Magdalena, 2013, "Indebted Mexicans in the Californian Mortgage Crisis", en Isabelle Guérin, Solène Morvant-Roux y Magdalena Villarreal (eds.), Microfinance, Debt and Over-Indebtedness. Juggling with Money, Routledge, Londres, pp. 46-63.

Zelizer, Viviana, 1994, The Social Meaning of Money, Princeton University Press, Nueva Jersey. 